\title{
Potential habitat suitability of Iraqi amphibians under climate change
}

\author{
EMAD KAKY $\mathbf{1}^{1,2,3, \bullet}$ \\ ${ }^{1}$ Research Centre, Sulaimani Polytechnic University. Qirga District, Sulaymaniyah, Iraq. `email: emadd.abbas@ spu.edu.iq \\ ${ }^{2}$ Kalar Technical Institute, Sulaimani Polytechnic University, Sulaymaniyah, Iraq \\ ${ }^{3}$ School of Life Sciences, University of Nottingham, Nottingham, United Kingdom
}

Manuscript received: 30 November 2019. Revision accepted: 23 January 2020.

\begin{abstract}
Kaky E. 2020. Potential habitat suitability of Iraqi amphibians under climate change. Biodiversitas 21: 731-742. Biodiversity management and conservation planning are two techniques for reducing the rate of biodiversity loss, especially under the effect of climate change. Here 289 records of five species of amphibians from Iraq and seven environmental variables were used with MaxEnt to predict potential habitat suitability for each species under current and future conditions, using the 5th IPCC assessment (RCP 2.6 and RCP 8.5 for the year 2050). The models suggest that annual precipitation and the mean temperature of the wettest quarter are the main factors that shape the distributions of these species. The estimated current habitat suitability was closely similar to that for 2050 under both scenarios, with a high niche overlap between them for all species. Among species, there were low niche overlaps between the frogs Bufo viridis, Hyla savignyi and Rana ridibunda, and also between the salamanders Neurergus crocatus and Neurergus microspilotus. Future sampling should focus on areas not currently covered by records to reduce bias. The results are a vital first step in long-term conservation planning for these species. Via sharing these results with decision-makers and stakeholders a crucial conservation actions need to increase Iraqi Protected Areas to avoid losing biodiversity in Iraq especially the unique populations and threaten species.
\end{abstract}

Keywords: Conservation, Iraq, global warming, MaxEnt, Species Distribution Modelling

\section{INTRODUCTION}

In the last few decades, it has become obvious to both scientists and the public that we are living in a period of extraordinary biodiversity crises. Thousands or perhaps tens of thousands of taxa and millions of unique populations are expected to become extinct in the wild under the effects of rapid climate changes (MEA 2005). This is the first time in the history of life that so many species have been threatened over such a short time. If the losses continue, a massive extinction will result in which the planet loses about $75 \%$ of species over the next few centuries (Monastersky 2014).

Climate change is estimated to become a more important factor in biodiversity loss over time (Monastersky 2014). The Intergovernmental Panel on Climate Change (IPCC) predicts that global temperatures will increase by about $0.2^{\circ} \mathrm{C}$ for each decade in the future, depending on $\mathrm{CO}_{2}$ emission levels (IPCC 2014). Many studies report that climate change has the potential to shift global species distributions (Alkemade et al. 2010; Thuiller et al. 2005; Araújo et al. 2006), especially towards more northern parts of the globe (Parmesan and Yohe 2003; Root et al. 2003). Prevention of these extinctions is vital to protect our planet and ecosystems. The protection of biological diversity at all levels (species, genetics, and ecosystems) is fundamental to ecosystem and conservation planning, with all three levels essential for wildlife and human survival (MEA 2005)

Species distribution modeling is a common and effective way of assembling and presenting the spatial distributions of different taxa, including amphibians (e.g.
Gasc et al. 1997). Many different methods, tools, and protocols have been developed recently to study distributions and the impact of climate change. Species distribution models (SDMs) provide useful information in terms of habitat suitability, and help to find the climate conditions for future adaptation in terms of conservation (Franklin 2009). SDMs estimate the relationships between environmental predictors and species presence or abundance (Elith and Leathwick 2009; Warren and Seifert 2011), providing new tools to explore and gain insights into different questions in conservation, evolution, and ecology (Elith et al. 2006). They are widely used to study the effects of climate change on conservation planning (Araujo et al. 2011; Dobrovolski et al. 2014; Kaky and Gilbert 2017, 2019a; de Luis et al. 2019). Their validity and power have been criticized in the literature because they lack mechanisms (Hampe 2004; Ibáñez et al. 2006), but they have proved their accuracy in many studies in predicting habitat suitability, and whether ranges will decrease or increase under climate change (Araújo and Rahbek 2006; Fois et al. 2016). SDMs are particularly good for evaluating the niches of poorly known species (Fois et al. 2018) and in developing countries with sparse data (Kaky and Gilbert 2016, 2019b). They can be used to guide sampling to find new previously unknown populations (Fois et al. 2015).

Iraq is an example of a country that does not have upto-date information on its biodiversity because of the conflicts since 1980, hampering conservation planning. Iraqi amphibians represent one taxon about which not enough is known, even globally (IUCN 2019). Amphibians face a higher extinction rate compared with 
other taxa, with $41 \%$ of them threatened (Monastersky 2014). According to the United Nations Environmental Programme (UNEP 2019) biodiversity in Iraq has four main threats: lack of an organization or legal system for conservation; lack of a proper Protected Areas network; no action plan, techniques or strategies for biodiversity conservation on a national scale; and numerous threatened species because of ecosystem degradation, especially the loss of the Mesopotamian marshlands and from oil spills (NRBI 2010). The ratio of land that is nominally protected as reserves in Iraq is about 1.5\% (UNEP-WCMC 2019), and a great deal more effort is required to achieve the Aichi Target 11 of $17 \%$ by 2020 (CBD 2010). Iraq needs more plans and strategies to develop its capabilities in biodiversity management and conservation, to counter the various effects of habitat destruction, land-use degradation, fragmentation, increasing population density, climate change and so on.

This study aims to find suitable habitat conditions for Iraqi amphibians under climate change using SDMs. These conditions are of course determined by both biotic and abiotic factors (Wiens 2011; Wisz et al. 2013), but abiotic conditions are known to be important (Abdelaala et al. 2019). A set of abiotic environmental variables are used to predict habitat suitability, both currently and in the future under climate change using two emission-scenario pathways of the $5^{\text {th }}$ IPCC assessment. The potential habitat suitability maps can then be used as initial priority locations for conservation planning in the near future.

\section{MATERIALS AND METHODS}

\section{Study species}

Iraq (Figure 1) has ten species of amphibian, in this study five of them have been used, consisting of three species of frog (Bufo viridis, Hyla savignyi and Rana ridibunda), and two of salamander (Neurergus crocatus and Neurergus microspilotus) with 289 occurrence records (see Table 1, Figure 2.A). The occurrence points are presence-only records collected from different sources for example online resources like VertNet (http: //portal.vertnet.org/), literature, and filed work. To avoid overfitting or imprecise predictions the species with less than ten records deleted (Baldwin 2009). Based on the IUCN Red List version 2019-2 two of the frogs (Hyla and Rana) are categorized as Least Concern with stable populations, but Bufo viridis is Data Deficient (Avci et al. 2015). The two salamanders are endemic to the region of Iraq, Iran, and Turkey (Sayım et al. 2009; Najafi-Majd and Kaya 013). According to the IUCN Red List, both salamanders are under threat of extinction. Neurergus microspilotus is Critically Endangered (Sharifi et al. 2009), and Neurergus crocatus is Vulnerable (Papenfuss et al. 2016).

\section{Current and future climate data}

Interpolated from climate data from the period 19502000, 19 environmental factors (Table 2) obtained from the WorldClim dataset (Hijmans et al. 2005; http:
//www.WorldClim.org) were used as predictors that might impact the distribution of Iraqi amphibians. These data were considered to indicate current climatic conditions. A resolution of 30 arc-seconds $(\sim 1 \mathrm{~km})$ has been choosing to run the model. The Variance Inflation Factor (VIF) was used to reduce collinearity among the environmental variables, excluding those with VIFs greater than 10 (using the 'sdm' package of R: Naimi and Araújo 2016). After evaluation, seven environmental variables were retained to run the model (see Table 2).

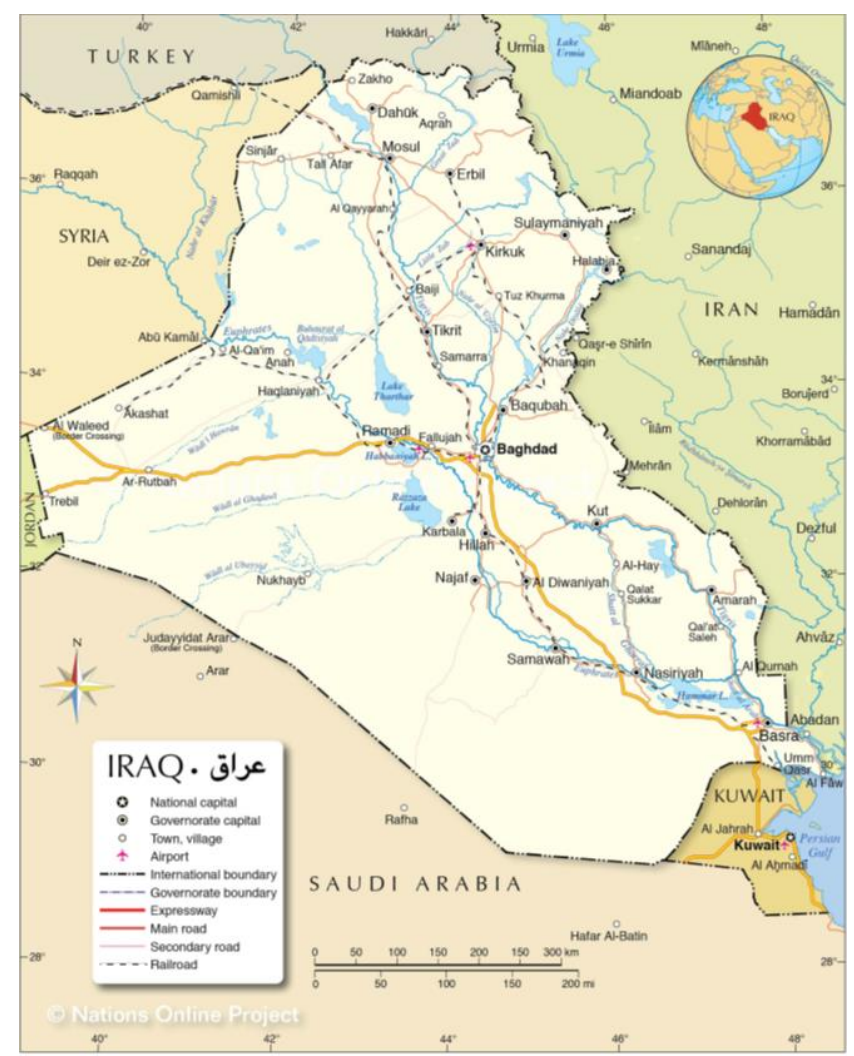

Figure 1. Political map of Iraq showing international borders, the national capital Baghdad, governorate capitals, major cities, main roads, railroads, and major airports.

//www.nationsonline.org/oneworld/map/iraq_map.htm)

Table 1. checklist of Iraqi amphibian and occurrence number.

\begin{tabular}{llc}
\hline \multicolumn{1}{c}{ Family } & \multicolumn{1}{c}{ Species } & $\begin{array}{c}\text { Occurrence } \\
\text { no. }\end{array}$ \\
\hline Bufonidae & Bufotes surdus (Bufo viridis) & 2 \\
& Bufotes variabilis & 99 \\
Hylidae & Hyla savignyi & 59 \\
Pelobatidae & Pelobates syriacus & 0 \\
Ranidae & Pelophylax bedriagae & 1 \\
& Pelophylax ridibundus (Rana & 108 \\
& ridibanda) & 11 \\
Salamandridae & Neurergus crocatus & 12 \\
& Neurergus derjugini & 0 \\
& Ommatotriton vittatus & 2 \\
\hline
\end{tabular}


Table 2. List of 19 environmental predictors available in the WorldClim Version 2 dataset. The highlighted one were used to build the model after reducing collinearity using Variation Inflated Factors (VIF)

BIO1 = Annual Mean Temperature
BIO2 $=$ Mean Diurnal Range $($ Mean of monthly $($ max temp - min temp $)$
BIO3 $=$ Isothermality $(\mathrm{BIO} / \mathrm{BIO})(* 100)$
BIO4 $=$ Temperature Seasonality $($ standard deviation $* 100)$
BIO5 $=$ Max Temperature of Warmest Month
BIO6 $=$ Min Temperature of Coldest Month
BIO7 $=$ Temperature Annual Range $($ BIO5-BIO6 $)$
BIO8 $=$ Mean Temperature of Wettest Quarter
BIO9 $=$ Mean Temperature of Driest Quarter
BIO10 $=$ Mean Temperature of Warmest Quarter
BIO11 $=$ Mean Temperature of Coldest Quarter
BIO12 $=$ Annual Precipitation
BIO13 $=$ Precipitation of Wettest Month
BIO14 $=$ Precipitation of Driest Month
BIO15 $=$ Precipitation Seasonality $($ Coefficient of Variation $)$
BIO16 $=$ Precipitation of Wettest Quarter
BIO17 $=$ Precipitation of Driest Quarter
BIO18 $=$ Precipitation of Warmest Quarter
BIO19 $=$ Precipitation of Coldest Quarter

To predict the impact of climate change, models were projected into one future time (2050) under different IPCC scenarios of the 5th assessment (Riahi et al. 2017; van Vuuren et al. 2011). The predicted environmental data were downloaded from WorldClim for two 'representative concentration pathways' (RCP 2.6 and RCP 8.5), generated by the UK Hadley Centre for Climate Prediction and Research (Hadgem2_es). RCP 2.6 characterizes an optimistic prediction representing a medium level of population growth, and very low greenhouse gas concentrations; while RCP 8.5 represents a pessimistic prediction characterized by high population growth and high levels of greenhouse gas concentrations by the end of 2100 (Wayne 2013).

\section{Species distribution modeling}

Maximum Entropy (Maxent) v3.4.1k (Phillips et al. 2006) was chosen as the modeling method because it uses presence-only data and has been used extensively for species distribution modeling (e.g. Elith et al. 2011; Slater and Michael 2012; de Araújo et al. 2014; Kaky and Gilbert 2017). It generates a sample of 10000 points from the area of study to characterize the environmental background (Anderson and Gonzalez 2011).

The default settings in Maxent have proven ability to achieve good performance (Phillips and Dudik 2008), and so were used here. I chose Cloglog output format (see Phillips et al. 2017), maximum iterations $=500$, convergence threshold $=10^{-5}$, regularization multiplier $=1$, $10 \%$ percentile presence threshold rule and cross-validation [K=10] with 10 replicates [for estimation error]. In the last setting, occurrence records are divided into $\mathrm{K}$ equal-sized groups, one of which is used for evaluation and the rest for calibration of the model. Every group is utilized once as an evaluation dataset, and every occurrence point appears exactly once in an evaluation dataset (Peterson et al. 2011). Here a target-group bias file has been used followed (Phillips et al. 2006), using SDMtools (Brown et al. 2017) in ArcGIS using a Gaussian kernel estimation function, this bias file will promote to select more background points from biased areas.

To evaluate model accuracy, I used the area under the curve (AUC: Fielding and Bell, 1997; Pearce and Ferrier 2000) and true skill statistic (TSS: Allouche et al. 2006). AUC values range from 0 to 1 : close to one indicates perfect discrimination, while values close to 0.5 are no better than random; values less than 0.5 indicate a performance worse than random (Phillips et al. 2006). TSS values range between -1 to +1 : any value close to +1 shows perfect model performance, whereas close to -1 indicates that model performance is no better than random (Allouche et al. 2006).

Binary maps (suitable/non-suitable) can be created in Maxent from the probabilities of occurrence by choosing a threshold rule (see Liu et al. 2005). In this study, the $10 \%$ percentile presence threshold rule was used to allow for georeferencing errors (Morueta-Holme et al. 2010; Kaky and Gilbert 2017). The threshold was applied to each of the ten replicate maps from the cross-validation. Maxent does not naturally give an average binary map over all the replicates, and so this was made manually by allotting 'presence' to a pixel that had presence values in more than $50 \%$ of the model runs (i.e. $>5$ replicates). The process was carried out using the Raster Calculator of ArcGIS10.2.2.

Losses and gains were calculated from the binary maps for each species by subtracting the future from current map (following Broennimann et al. 2006; Hatten et al. 2016; Thuiller et al. 2005) to identify the areas of consistent presence, expansion, and contraction under each of the climate change scenarios. Finally, the habitat suitability maps were used to calculate the niche overlap among the species, and also between the current and future maps of each species (Warren et al. 2008; Widick and Bean 2019). This relies on habitat suitability being a suitable estimate of the niche (Wiens et al. 2010; Widick and Bean 2019). Here I used Schoener's $D$ (Warren et al. 2008) implemented by ENMTools: this index ranges between 0 (no overlap) to 1 (total overlaps). 


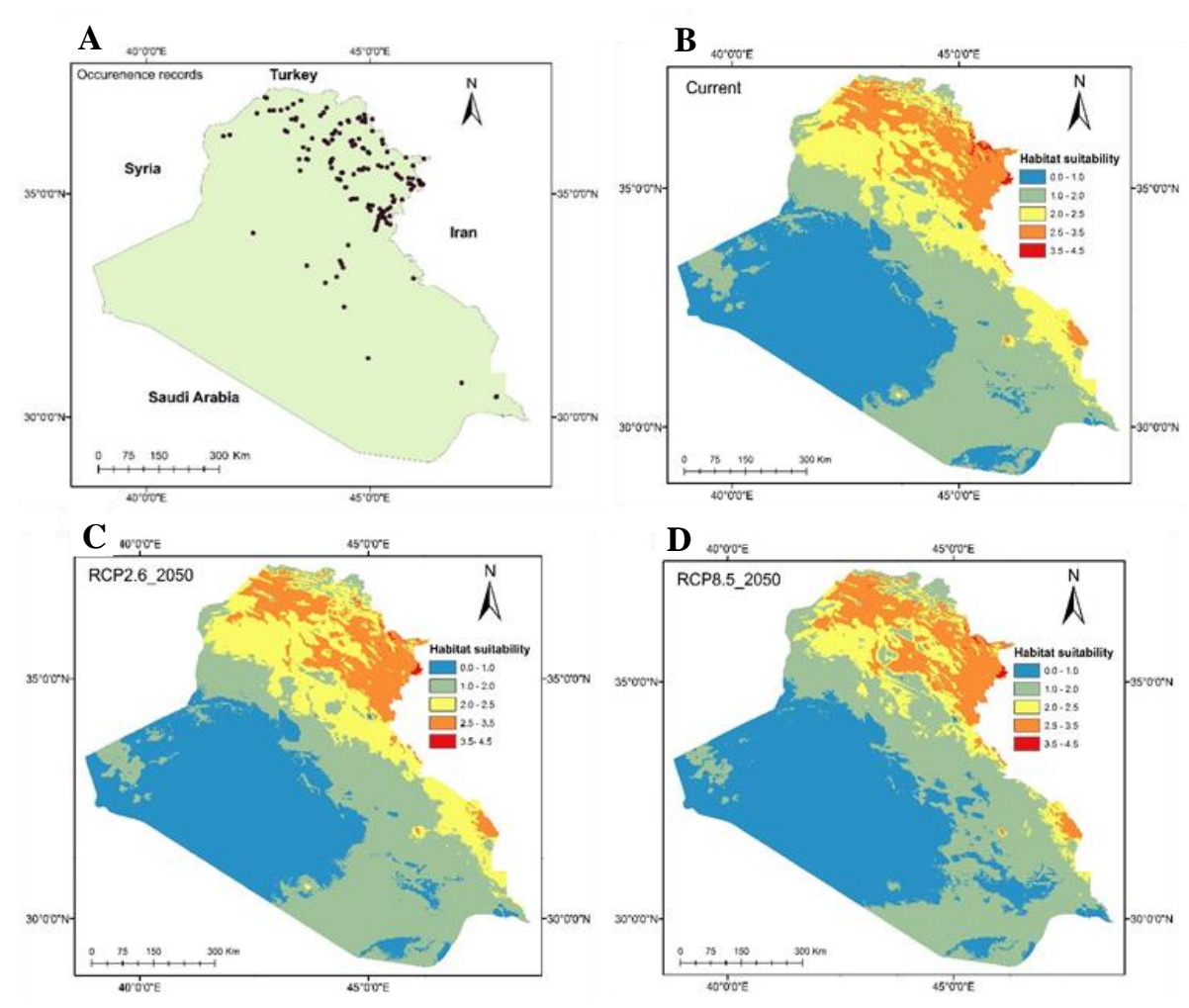

Figure 2. A. Occurrence records for all species; B-D. Pattern of predicted species richness (really, the sum of habitat suitability) of Iraqi amphibians for the current (B) and future scenarios (C, D). The color ramp for the pattern of predicted species richness runs from red (high) to blue (low)

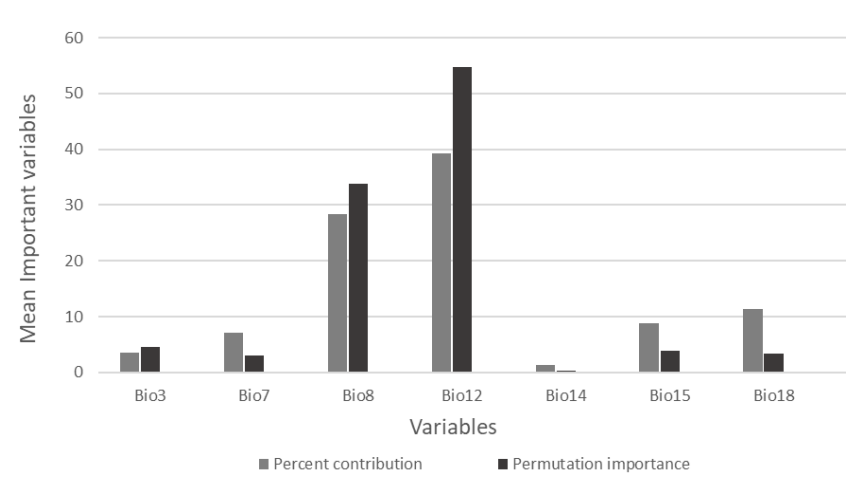

Figure 3. Average importance of the predictor variables based on both percent contribution and permutation importance in the MaxEnt final models

\section{RESULTS AND DISCUSSION}

\section{Results}

The performance of the models was very good in terms of the mean AUC $(0.90 \pm 0.07 \mathrm{SD})$ and TSS $(0.69 \pm$ 0.11 ), which shows that the models were suitable for use in extrapolation (see Table 3). The good AUC and TSS values were recorded for species with both low and high sample sizes. The most important environmental variables in the models were Bio12 (annual precipitation) for the three frogs and Bio8 (mean temperature of the wettest quarter) for the two salamanders, as assessed by both indicators (percent contribution and permutation importance) (Figure 3, Figure 7, Table 4). The response curves show that the frogs prefer climate conditions of annual rainfall between $150-800 \mathrm{~mm}$, and mean temperatures of the wettest quarter of between $0-18^{\circ} \mathrm{C}$, while the salamanders prefer wetter and colder conditions (Figure 4). The models predict that the species survive in wet climate conditions.

In the current time, the northern and northeastern parts of Iraq show the highest predicted habitat suitability for amphibians (Figure 2.B), especially around northern cities such as Mosul, Dohuk, Erbil, Sulaymaniyah and some parts of Kirkuk. The model predicts some areas with high suitability between Kut and Amarah in southeastern Iraq where there are few occurrence records (cf. Figure 2.B). There were also areas of high habitat suitability across the entire border between Iraq and Iran, from north to south (Figure 2.B; Figure 5). The future climate scenarios showed slightly larger habitat suitability overall (Figure 2.C, D), especially under the pessimistic RCP8.5 (Figure 2.D). There is high consistency in the pattern of predicted habitat suitability between the current and future scenarios (Figure 2.B-D; Table 5). The net predicted habitat suitability in the future decreased slightly for the two salamanders (Table 5). The predicted expansion of habitat suitability for frogs was primarily towards the northeast and the border between Iraq and Iran.

From the binary maps, all species both gained and lost areas of habitat suitability under each of the predicted 
future scenarios (Table 6). Under RCP2.6, three species gain habitat suitability (Hyla savignyi by 27,989 $\mathrm{km}^{2}$; Rana ridibunda by $6,333 \mathrm{~km}^{2}$, and Neurergus crocatus by $571 \mathrm{~km}^{2}$ ), while two species lost habitat suitability (Bufo viridis by $10,512 \mathrm{~km}^{2}$ and Neurergus microspilotus by $9,301 \mathrm{~km}^{2}$ ) (for more details, see Table 6 and Figure 6). Under the RCP8.5 scenario, four of the species gained habitat suitability, while Neurergus microspilotus lost habitat suitability. Thus, Neurergus microspilotus was predicted to lose habitat suitability under both future scenarios (see Table 6; Figure 6).

The results showed a high intraspecific niche overlap between the current and future scenarios for all species. The niche similarity ranged between 0.87 and 0.98 . Among species, there was a high niche overlap between the frogs, while the salamanders showed moderate niche overlap. In general, there were low niche overlaps between any frog and either salamander (see Table 7 for the details).

\section{Discussion}

These results highlight the importance of establishing conservation planning to counter the effects of climate change for Iraqi amphibians, especially for species that are at risk of extinction. This is the first time that species distribution modeling has been applied to Iraqi amphibians, and further, there is no study applying SDM to climate change for any Iraqi taxon. This study is also novel in comprehensively mapping the occurrence locations of the Iraqi amphibians.

Evaluation of model performance is a vital step to determining the accuracy of SDMs and then the accuracy of the distributional predictions (Peterson et al. 2008). The results indicated good performance in terms of mean AUC and TSS scores: models are more reliable when both evaluation statistics agree (Beauregard and de Blois 2014). Some studies have stated that AUC by itself is not enough as an indicator of model accuracy (Austin 2007; Lobo et al. 2008), because of getting high AUC scores when there are few records (Jimenez-Valverde et al. 2008; Lobo et al. 2008). However, many large studies show that model accuracy does not depend on the number of occurrence records used to run the model (Elith et al. 2006; Newbold et al. 2009). I used two methods to evaluate the accuracy of my models (cf. Kaky and Gilbert 2016; Gillard et al. 2017; Smeraldo et al. 2018), but many recent studies use just AUC and these have apparently achieved good model performance (Phillips et al. 2006; Elith et al. 2006; Warren and Seifert 2011; Phillips et al. 2017).

Environmental conditions of mainly temperature and precipitation variables can be used to predict how species are distributed (Hannah 2011). My models show that these amphibians are more affected by annual precipitation and the mean temperature of the wettest quarter, perhaps unsurprising since they tend to live in wet conditions, especially the salamanders which live entirely in water. All species prefer wet climate conditions, and the response curves suggest that the frogs prefer precipitation between 150 and $800 \mathrm{~mm}$, but 200 to $1000 \mathrm{~mm}$ and cooler climate for the salamanders, which live in streams and mountain brooks with survival dependent on water quality (Sayım et al. 2009). The three frogs have high interspecific niche overlap demonstrating that they share the same climate conditions currently and under future climate scenarios, and hence probably share resources as well, so protection measures for these species are relatively straightforward in terms of reserves. Previous studies are also shown that different populations share the same environmental variables (Williams, 1992; Bean et al. 2014), with implications for conservation planning (Widick and Bean 2019). The salamanders have only moderate interspecific niche overlap, implying that they do not live in the same climate conditions, and hence will require separate consideration in conservation planning. The same is true between the frogs and salamanders, which require very different environmental conditions, and hence should be treated differently in terms of conservation (Widick and Bean 2019).

Table 3. The number of occurrence records of the species, the mean values of AUC and TSS, and the global IUCN Red List status.

\begin{tabular}{|c|c|c|c|c|}
\hline Species & $\begin{array}{l}\text { No. of } \\
\text { records }\end{array}$ & AUC & TSS & $\begin{array}{l}\text { IUCN } \\
\text { status }\end{array}$ \\
\hline $\begin{array}{l}\text { Bufo viridis (Bufotes } \\
\text { variabilis) }\end{array}$ & 99 & 86 & .64 & $\begin{array}{l}\text { DD/ } \\
\text { Unknown }\end{array}$ \\
\hline Hyla savignyi & 59 & 0.82 & 0.54 & $\mathrm{LC} /$ stable \\
\hline $\begin{array}{l}\text { Rana ridibanda } \\
\text { (Pelophylax ridibundus) }\end{array}$ & 108 & 0.87 & 0.63 & $\begin{array}{l}\text { LC/ } \\
\text { increasing }\end{array}$ \\
\hline Neurergus crocatus & 11 & 0.97 & 0.80 & $\begin{array}{l}\text { VU/ } \\
\text { decreasing }\end{array}$ \\
\hline Neurergus microspilotus & 12 & 0.99 & 0.82 & $\begin{array}{l}\mathrm{CR} / \\
\text { decreasing }\end{array}$ \\
\hline
\end{tabular}

Table 4. The important variables for each species.

\begin{tabular}{ll}
\hline Species & Important variables \\
\hline Bufo viridis & Annual precipitation \\
Hyla savignyi & Annual precipitation \\
Neurergus crocatus & Mean Temperature of Wettest Quarter \\
Neurergus microspilotus & Mean Temperature of Wettest Quarter \\
Rana ridibanda & Annual precipitation \\
\hline
\end{tabular}

Table 5. Predicted area of habitat suitability per species for current and future scenarios, calculated from the binary maps.

\begin{tabular}{lllc}
\hline \multicolumn{1}{c}{ Species } & \multicolumn{1}{c}{ Models } & $\begin{array}{c}\text { Area } \\
\left(\mathbf{k m}^{2}\right)\end{array}$ & \% of land \\
\hline Bufo viridis & Current & 124774 & 20 \\
& RCP 2.6_2050 & 115146 & 19 \\
& RCP 8.5_2050 & 132359 & 21 \\
Hyla savignyi & Current & 139347 & 23 \\
& RCP 2.6_2050 & 165622 & 27 \\
Rana ridibanda & RCP 8.5_2050 & 159699 & 26 \\
& Current & 115464 & 19 \\
Neurergus crocatus & RCP 2.6_2050 & 119335 & 19 \\
& RCP 8.5_2050 & 123188 & 20 \\
& Current & 20029 & 3 \\
Neurergus microspilotus & RCP 2.6_2050 & 19873 & 3 \\
& RCP 8.5_2050 & 20130 & 3 \\
& Current & 9988 & 2 \\
& RCP 2.6_2050 & 9263 & 1.5 \\
& RCP 8.5_2050 & 9534 & 1.5 \\
\hline
\end{tabular}


Table 6. Gains and losses of habitat suitability for each species between the current time and 2050 under two different climate scenarios $\left(\right.$ in $\mathrm{km}^{2}$ )

\begin{tabular}{|c|c|c|c|c|c|c|}
\hline \multirow[b]{2}{*}{ Species } & \multicolumn{3}{|c|}{ RCP 2.6_2050 } & \multicolumn{3}{|c|}{ RCP 8.5_2050 } \\
\hline & Suitability $\mathbf{k m}^{2}$ & Gain km² & Loss $\mathbf{k m}^{2}$ & Suitability $\mathbf{k m}^{2}$ & Gain $\mathbf{k m}^{2}$ & Loss $\mathbf{k m}^{2}$ \\
\hline Bufo viridis & 114,262 & 884 & 10,512 & 121,264 & 11,095 & 3,510 \\
\hline Hyla savignyi & 137,633 & 27,989 & 1,714 & 136,973 & 22,726 & 2,374 \\
\hline Rana ridibanda & 113,002 & 6,333 & 2,462 & 113,549 & 9,639 & 1,915 \\
\hline Neurergus crocatus & 19,302 & 571 & 727 & 19,959 & 171 & 70 \\
\hline Neurergus microspilotus & 9,104 & 159 & 884 & 9,301 & 233 & 687 \\
\hline
\end{tabular}
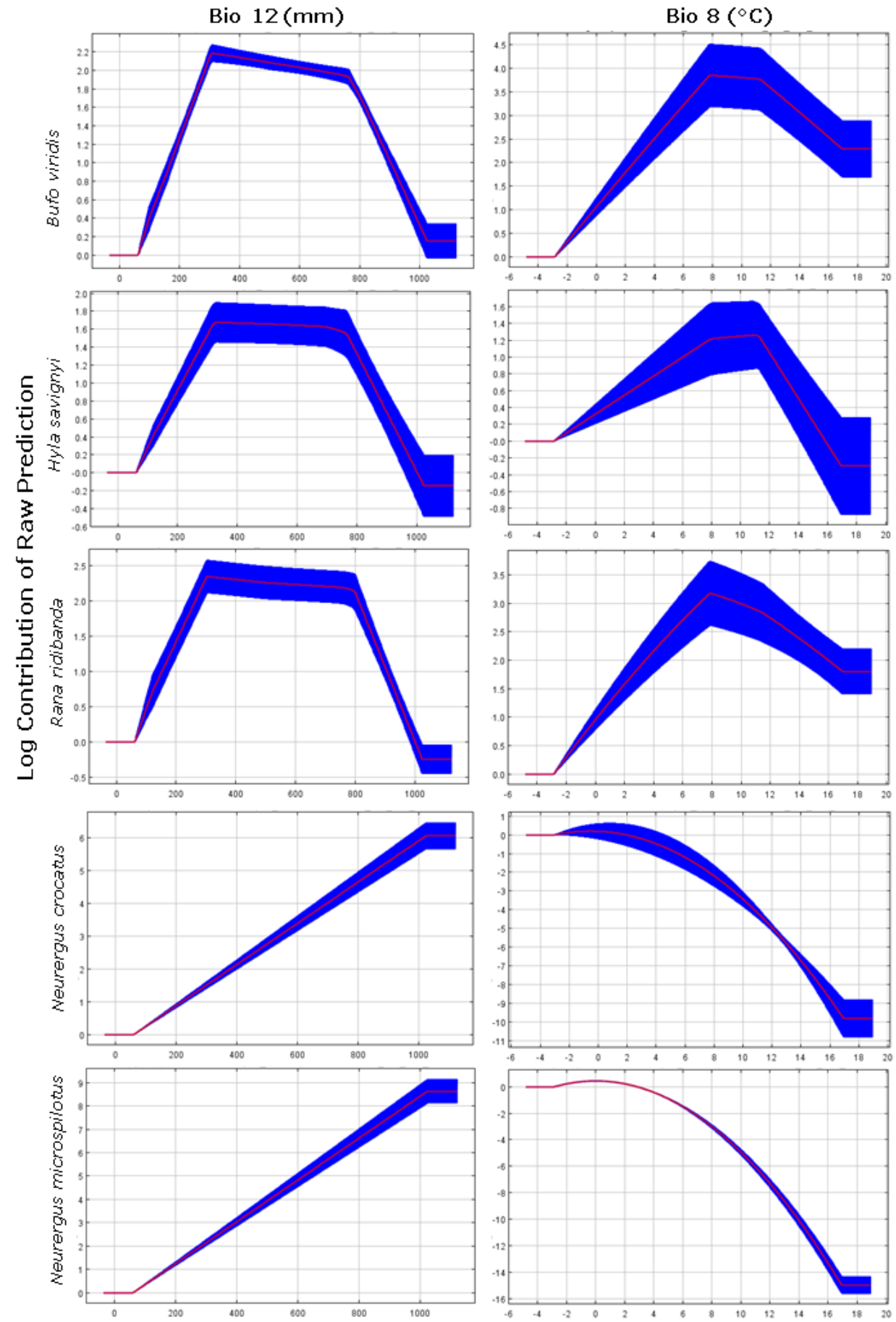

Figure 4. Response curves for the most important variables estimated by MaxEnt 

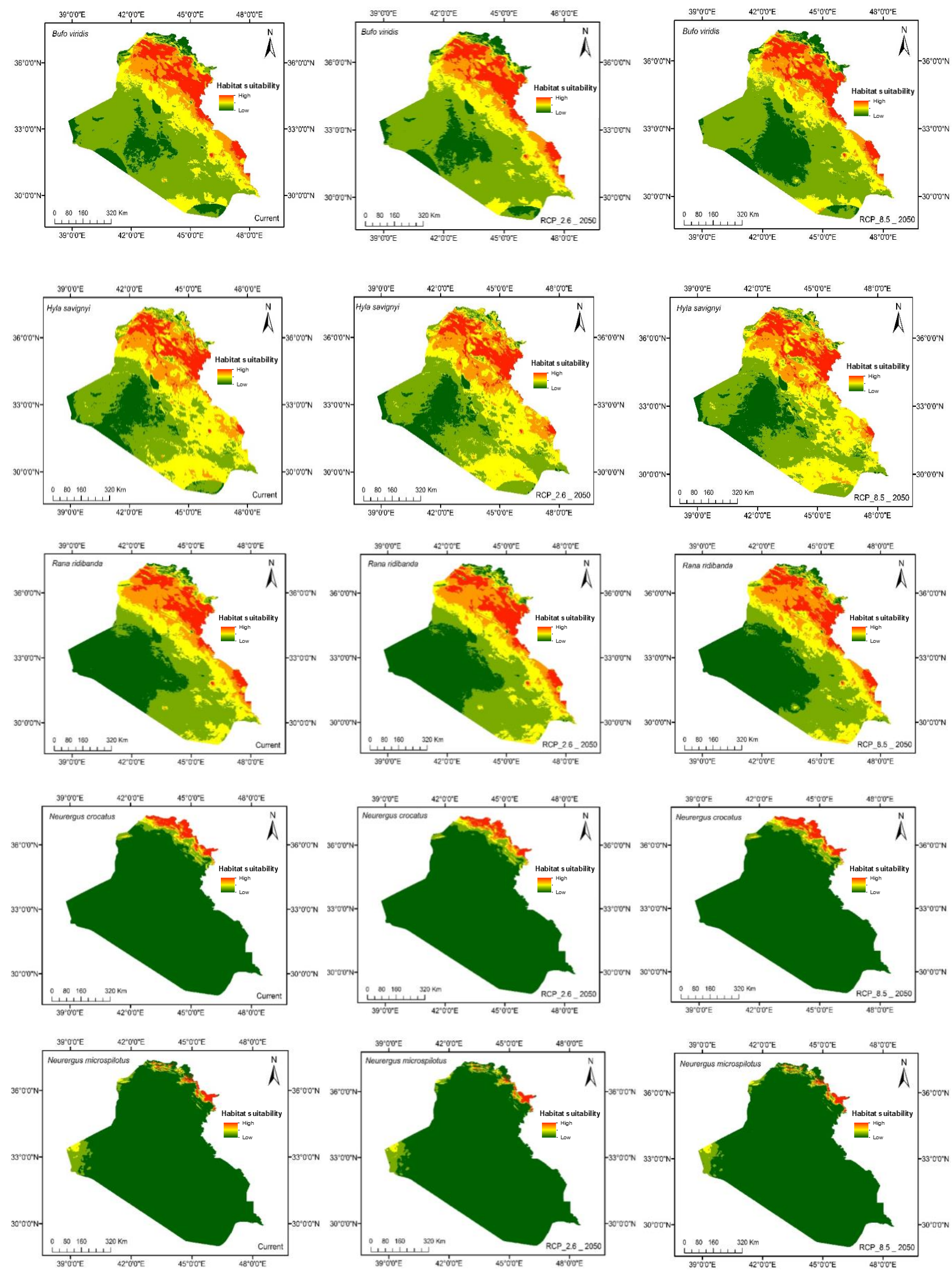

Figure 5. Pattern of predicted habitat suitability of Iraq's amphibians for each species at the current time and under future climate scenarios (RCP2.6 and RCP8.5_2050). 


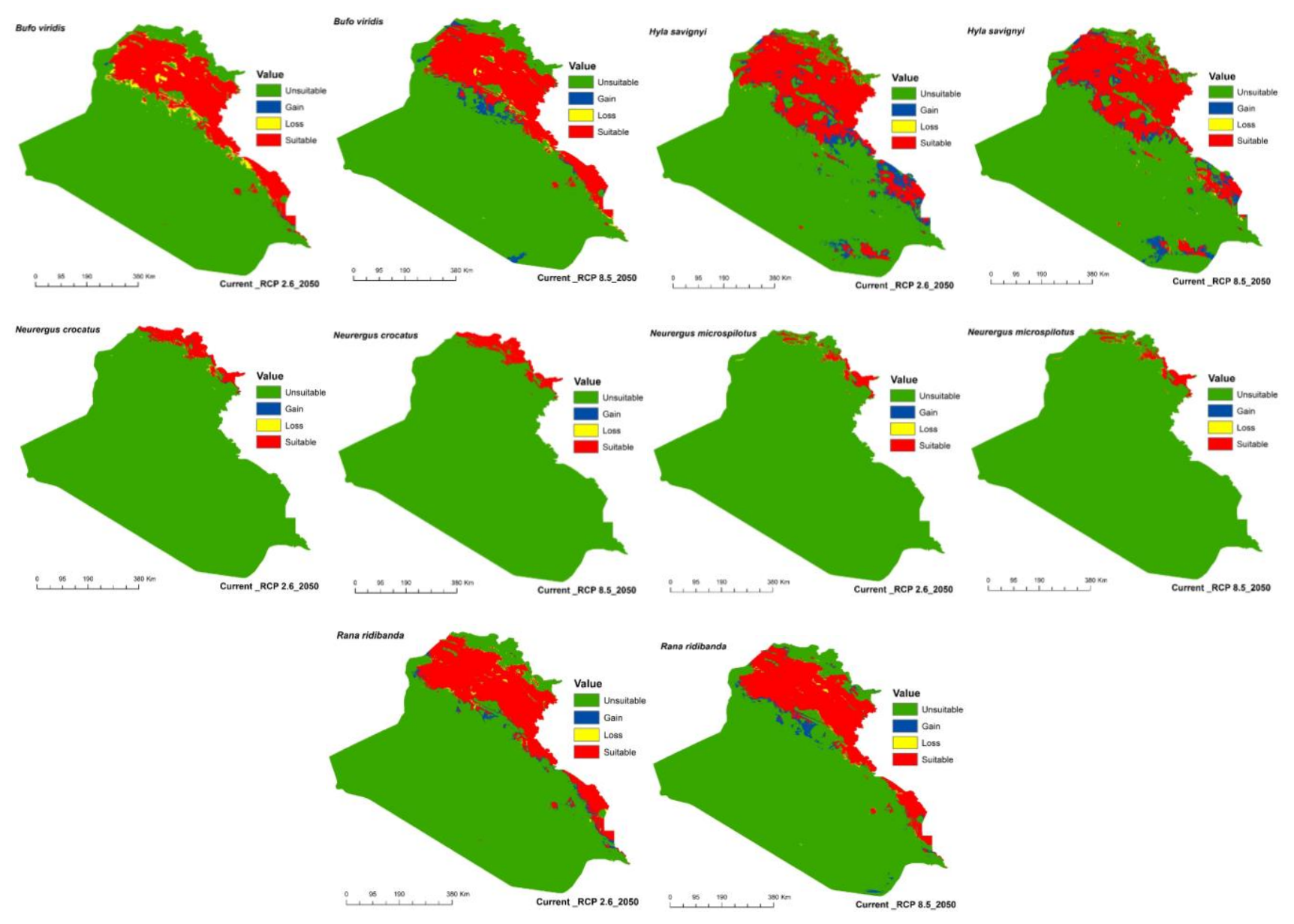

Figure 6. Pattern of predicted species loss and gain for each species
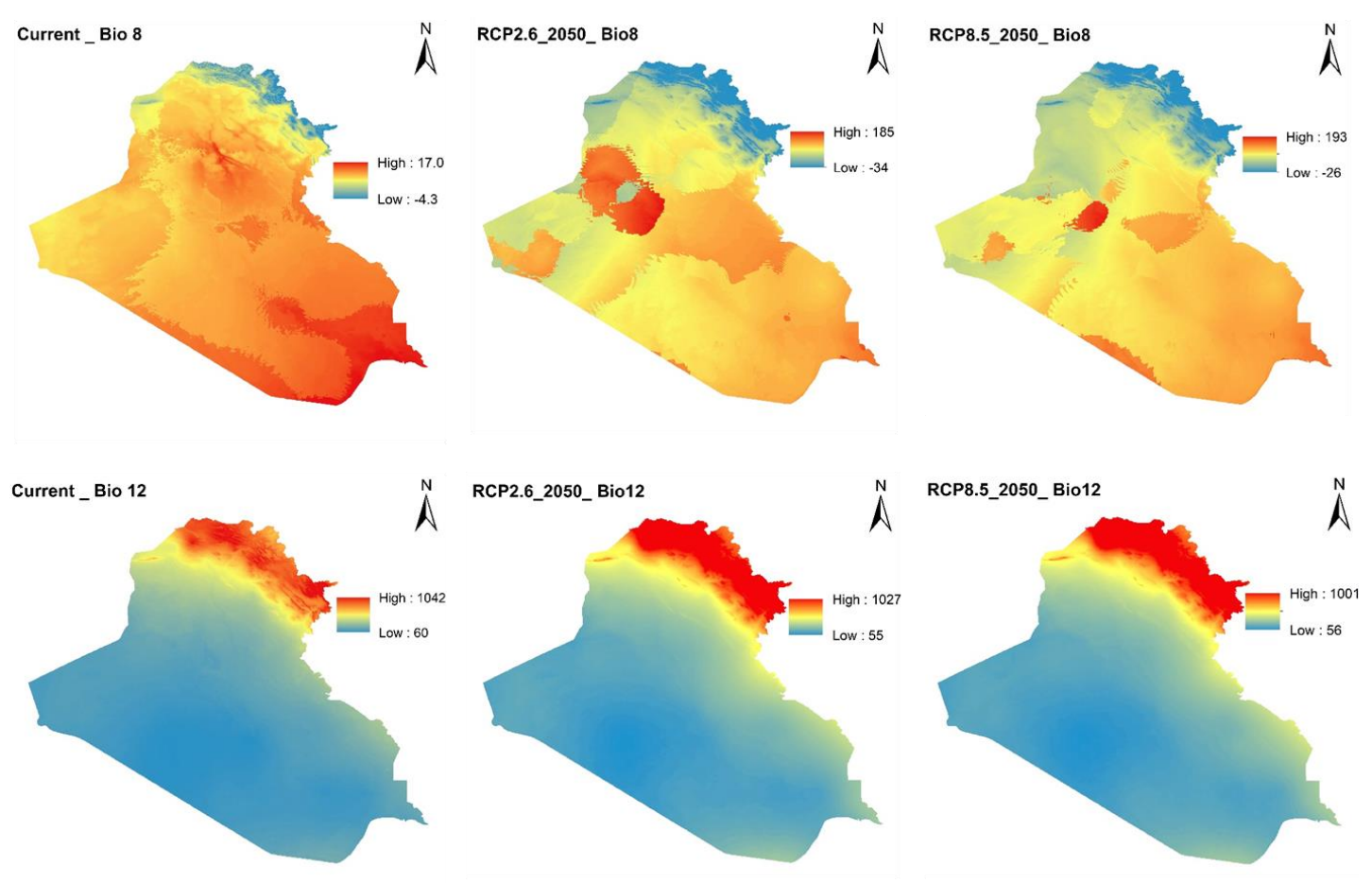

Figure 7. Current and future climate predicted maps for both Bio8 and Bio12 
Table 7. Niche overlap among and within species between current and future scenarios. High values mean high niche overlap and low values mean low niche overlap

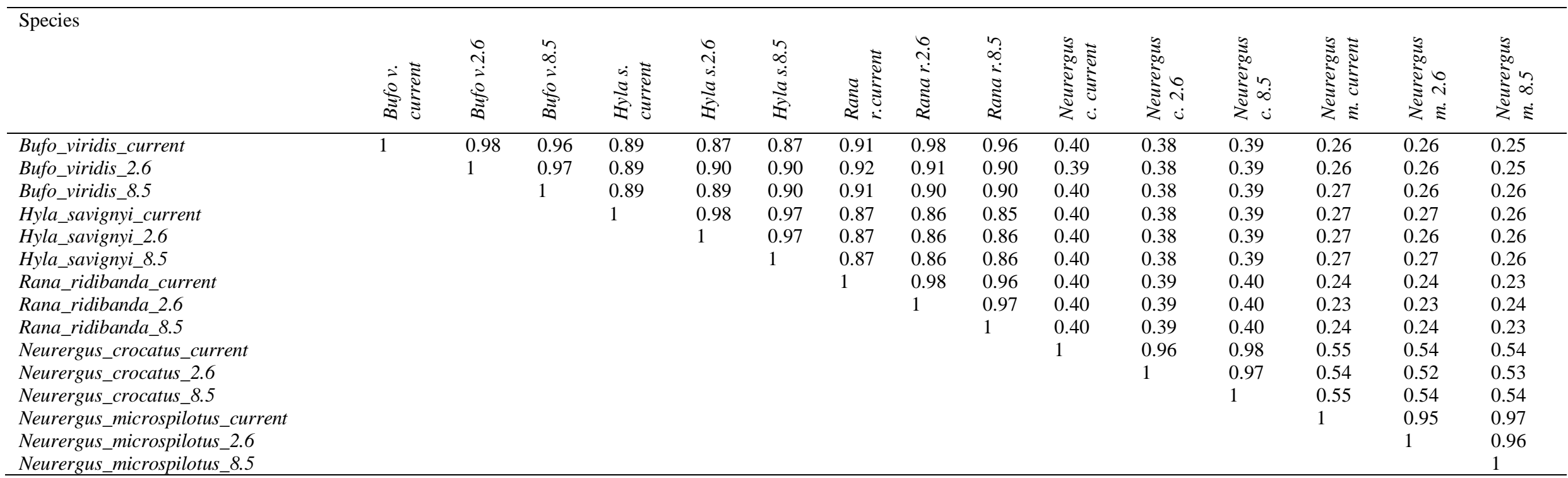


Habitat suitability under current and future scenarios appear almost stable, with more habitat suitability toward the northeastern parts of the study area and some scattered locations in the south-east. Many recent studies suggest that species are shifting to the north (Parmesan and Yohe 2003; Root et al. 2003), which is consistent with my results because amphibians prefer the wet conditions more available in the north-east (Sayım et al. 2009; Najafi-Majd and Kaya 2013). There are no studies of Iraqi amphibians for comparison. To protect and conserve these species, we cannot afford to wait for perfect data (Kaky and Gilbert 2016, 2017), especially in conflict countries such as Iraq. On the other hand, the target-group methods in MaxEnt applied to reduce this bias in our data (Phillips et al. 2009). The complexity of ecological systems shows the fundamental limits to modeling approaches because prediction uncertainties are unavoidable, but SDM techniques can give useful information (Pearson and Dawson 2003) especially when there are no range maps for any species and no local experts (Hawkins et al. 2008; Vasconcelos et al. 2012). The two salamanders occur only in very small locations, and based on the loss-gain maps these species will tend to lose more than they gain under climate change. Local disasters such as diseases, drought and land transformation by human activities, can easily cause extinction (Lawton and May 1995). The three frogs are predicted to gain more than lose in habitat suitability.

The endangered salamanders are very vulnerable to human activities, habitat loss, habitat changes, overharvesting and drought (Papenfuss et al. 2009). In some areas sheep and cattle destroyed their habitat through overgrazing and pollution of rivers and streams; local people use the streams for drinking water, and they kill salamanders because they expect them to be poisonous (Najafi-Majd and Kaya 2013). Globally all amphibians face the risk of extinction because of chytrid fungi (Monastersky 2014). Thus, urgent conservation for these salamanders is vital, as well as increasing the environmental awareness of the local authorities and local people in protecting them. Further surveys are very important for all five species to find new populations and new locations so that their niches can be mapped more accurately and reassessments of their Red List status can be carried out.

In conclusion, SDM is a good approach to estimate habitat suitability even with sparse data; it helps in guiding new surveys to save time and money. It does have limitations evident in this study, for example, the number of occurrence records, sampling bias, and poor knowledge of geographical distribution. The SDMs in this study also lacks any input of possible biotic influences, but this will require more sophisticated biological information about each species. Truly predictive biological models will incorporate the important biological mechanisms (e.g. evolution, environment, physiology, demography, dispersal, and species interactions: Urban et al. 2016) in a biologically realistic way, but such realism is a long way off. However, this is the first evaluation of possible changes in the distribution of Iraq's amphibians under climate change, providing important information for further studies. Despite their uncertainties, SDM methods represent an important tool to fight the Wallacean shortfall (Whittaker et al 2005; Hortal et al 2015), especially prediction under climate change scenarios (Guisan et al. 2013). These results can be used to spur preliminary action for conservation in Iraq by decision-makers. They supply new data for national and global evaluations, and will help find the best areas for nature reserves in Iraq to increase the proportion of protected land in Iraq, and perhaps to achieve the Aichi target 11 by 2020 .

\section{ACKNOWLEDGEMENTS}

We thank the Sulaimani Polytechnic University in Iraq for supporting this work; and Prof. Francis Gilbert for review the manuscript and valuable advice, Abdulaziz Alatawi and Victoria Nolan for advice; and, Aram Jaf for sharing the data. I would like to thank the anonymous reviewers and editor for their helpful assessments and comments on previous version of the manuscript.

\section{REFERENCES}

Abdelaala M, Foisa M, Fenua G, Bacchettaa G. 2019. Using MaxEnt modeling to predict the potential distribution of the endemic plant Rosa arabica Crép. in Egypt. Ecol Inform 50: 68-75.

Al-Barazengy AN, Salman AO, Hameed FTA. 2015. Updated list of amphibians and reptiles in Iraq 2014. Bull Iraq Nat Hist Mus 13: 2940 .

Allouche O, Tsoar A, Kadmon R. 2006. Assessing the accuracy of species distribution models: prevalence, kappa and the true skill statistic (TSS). J Appl Ecol 43: 1223-1232.

Anderson RP, Gonzalez I. 2011. Species-specific tuning increases robustness to sampling bias in models of species distributions: An implementation with Maxent. Ecol Model 222: 2796-2811.

Araújo MB, Rahbek, C. 2006. How does climate change affect biodiversity?. Science 313: 1396-1397.

Austin M. 2007. Species distribution models and ecological theory: a critical assessment and some possible new approaches. Ecol Model 200: 1-19.

Avci A, Tuniyev B, Isailovic JC, et al 2015. Bufotes variabilis. The IUCN Red List of Threatened Species 2015: e.T153571A74506381. DOI: 10.2305/IUCN.UK.2015-1.RLTS.T153571A74506381.en. October 2019].

Baldwin RA. 2009. Use of Maximum Entropy modeling in wildlife research. Entropy 11: 854-866.

Beauregard F, de Blois S. 2014. Beyond a climate-centric view of plant distribution: edaphic variables add value to distribution models. PLoS One 9: e92642. DOI: 10.1371/journal.pone.0092642.

Bean WT, Stafford R, Butterfield HS, Brashares JS. 2014. A multi-scale distribution model for non-equilibrium populations suggests resource limitation in an endangered rodent. PLoS One 9: e106638. DOI: 10.1371/journal.pone.0106638

Beck J, Böller M, Erhardt A, Schwanghart W. 2014. Spatial bias in the GBIF database and its effect on modeling species' geographic distributions. Ecol Infs 19: 10-15.

Broennimann O, Thuiller W, Hughes G, Midgley GF, Alkemade JMR, Guisan A. 2006. Do geographic distribution, niche property and life form explain plants' vulnerability to global change? Global Ch Biol 12: 1079-1093.

Brown JL, Bennett JR, French CM. 2017. SDMtoolbox 2.0: the next generation 326Python-based GIS toolkit for landscape genetic, biogeographic and species 327distribution model analyses. PeerJ 5: e4095. DOI: 10.7717 /peerj.4095

CBD. Decision Adopted by the Conference of the Parties to the Convention of Biological Diversity at its Tenth meeting. Convention on Biological Diversity. 2010. www.cbd.int/sp/ 
de Araújo C. B, Marcondes-Machado L. O, Costa G. C, Silman M. 2014. The importance of biotic interactions in species distribution models: a test of the Eltonian noise hypothesis using parrots. J Biogeogr 41: 513-523.

de Luis M, Alvarez-Jimenez J, Martı'nez Labarga J. M, Bartolome' C. 2019. Four climate change scenarios for Gypsophila bermejoi G Lopez (Caryophyllaceae) to address whether bioclimatic and soil suitability will overlap in the future. PLoS One 14 (6): e0218160. DOI: 10.1371/journal.pone.0218160.

Elith J, Phillips SJ, Hastie T, Dudík M, Chee YE, Yates CJ. 2011. A statistical explanation of MaxEnt for ecologists. Divers Distrib 17 43-57.

Elith J, Graham C. H, Anderson R. P, Dudik, M. et al. 2006. Novel methods improve prediction of species' distributions from occurrence data. Ecography 29: 129-151.

Elith J, Leathwick J. R. 2009. Species distribution models: ecological explanation and prediction across space and time. Ann Rev Ecol Evol Syst 40: 677-697.

Franklin J. 2009. Mapping species distributions: spatial inference and prediction, 1st ed. Cambridge University Press, New York.

Fois M, Fenu G, Cuena Lombraña A, Cogoni D, Bacchetta G. 2015. A practical method to speed up the discovery of unknown populations using Species Distribution Models. J Nat Conserv 24: 42-48

Fois M, Cuena-Lombraña A, Fenu G, Cogoni D, Bacchetta G. 2016. The reliability of conservation status assessments at regional level: past, present and future perspectives on Gentiana lutea L. ssp. lutea in Sardinia. J Nat Conserv 33: 1-9. DOI: 10.1016/j.jnc.2016.06.001.

Fois M: Cuena-Lombraña A, Fenu G, Bacchetta G. 2018. Using species distribution models at local scale to guide the search of poorly known species: review, methodological issues and future directions. Eco Model 385: 124-132.

Frost DR. 2017. Amphibian species of the world: An online reference Version 6.0 (1/JUN/2019). Electronic Database accessible at http: // research.amnh.org/herpetology/amphibia/index.html. American Museum of Natural History, New York, USA.

Gasc JP, Cabela A, Crnobrnja-Isailovic J, Dolmen D, Grossenbacher K, Haffner P, Lescure J, Martens H, Martínez Rica JP, Maurin H, Oliveira ME, Sofianidou TS, Veith M, Zuiderwijk A. (Eds), 1997. Atlas of amphibians and reptiles in Europe. Societas Europaea Herpetologica, Muséum National d'Histoire Naturelle \& Service du Patrimoine Naturel, Paris.

Gillard M, Thiébaut G, Deleu C, Leroy B. 2017. Present and future distribution of three aquatic plants taxa across the world: decrease in native and increase in invasive ranges. Biol Invas 19 (7): 2159-2170.

Ibáñez I, Clark JS, Dietze MC, Feeley K, Hersh M, LaDeau S, McBride A, Welch NE, Wolosin MS. 2006. Predicting biodiversity change: outside the climate envelope, beyond the species-area curve. Ecology 87: $1896-1906$

IPCC 2014. Climate Change 2014: Synthesis Report. Contribution of Working Groups I, II and III to the Fifth Assessment Report of the Intergovernmental Panel on Climate Change. In: Core Writing Team, Pachauri RK, Meyer LA (eds.). Intergovernmental Panel on Climate Change. Geneva, Switzerland.

Hampe A. 2004. Bioclimate envelope models: what they detect and what they hide. Global Ecol Biogeogr 13: 469-471

Hannah L. 2011. Climate Change Biology, Elsevier Ltd., New York.

Hatten JR, Giermakowski JT, Holmes JA, Nowak EM, Johnson MJ, Ironside KE III, CvR, Peters M, Truettner C, Cole KL. 2016. Identifying Bird and Reptile Vulnerabilities to Climate Change in the Southwestern United States: US Geological Survey open-file report 2016-1085. USGS, Washington, DC.

Hawkins BA. et al. 2008. What do range maps and surveys tell us about diversity patterns? Folia Geobot 43: 345 - 355.

Hernandez PA, Graham CH, Master LL, Albert DL. 2006. The effect of sample size and species characteristics on performance of different species distribution modeling methods. Ecography 29: 773-785.

Hijmans RJ, Cameron SE, Parra JL, Jones PG, Jarvis A. 2005. Very high resolution interpolated climate surfaces for global land areas. Intl J Clim 25: 1965-1978.

Hortal J, de Bello F, Diniz-Filho JAF, Lewinsohn TM, Lobo JM, Ladle RJ. 2015. Seven shortfalls that beset large-scale knowledge of biodiversity. Ann Rev Ecol Evol Syst 46: 523-549.

Jimenez-Valverde A, Lobo J.M, Hortal J. 2008. Not as good as they seem: the importance of concepts in species distribution modelling. Divers Distrib 14: 885-890. den Bosch H. 2003. Iraqi Herpetology_an Introductory Checklist. Institute of Biology, Leiden University, Netherlands.

Kaky E, Gilbert F. 2016. Using species distribution models to assess the importance of Egypt's protected areas for the conservation of medicinal plants. J Arid Environ 135: 140-146.

Kaky E, Gilbert F. 2017. Predicting the distributions of Egypt's medicinal plants and their potential shifts under future climate change. PLoS One 12: e0187714. DOI: 10.1371/journal pone.0187714

Kaky E, Gilbert F. 2019a. Allowing for human socioeconomic impacts in the conservation of plants under climate change. Plant Biosyst. DOI: 10.1080/11263504.2019.1610109.

Kaky E, Gilbert F. 2019b. Assessment of the extinction risks of medicinal plants in Egypt under climate change by integrating species distribution models and IUCN Red List criteria. J Arid Environ 179, 1-9 . doi.org/10.1016/j.jaridenv.2019.05.016.

Lawton JH, May RM. 1995. Extinction Rates. Oxford Univ. Press, Oxford.

Lobo JM, Jimenez-Valverde A, Real R. 2008. AUC: a misleading measure of the performance of predictive distribution models. Global Ecol Biogeogr 17: 145-151.

MEA. 2005. Ecosystems and Human Well-Being: Biodiversity Synthesis. World Resources Institute, Washington, DC.

Monastersky R. 2014. Biodiversity: Life-a status report. Nature 516: 158161.

Morueta-Holme N, Flojgaard C, Svenning JC. 2010. Climate change risks and conservation implications for a threatened small-range mammal species. PLoS One 5: e10360.

Naimi B, Araújo MB. 2016. sdm: a reproducible and extensible R platform for species distribution modelling. Ecography 39: 368-375.

Najafi-Majd E, Kaya U. 2013. Rediscovery of the Lake Urmia newt, Neurergus crocatus Cope, 1862 (Caudata: Salamandridae) in northwestern Iran after 150 years. Amphib Reptile Conserv 6: 36-41.

NRBI [National Report on Biodiversity in Iraq]. 2010. Iraq fourth national report to the convention on biological diversity. Ministry of Environment, Republic of Iraq, Baghdad.

Newbold T, Reader T, Zalat S, El-Gabbas A, Gilbert F. 2009. Effect of characteristics of butterfly species on the accuracy of distribution models in an arid environment. Biodivers Conserv 18: 3629-3641.

Papenfuss T, Sparreboom M, Ugurtas I.H, Rastegar-Pouyani N, Kuzmin S, Anderson S, Eken G, Kiliç T, Gem E, Kaya U. 2009. Neurergus crocatus (errata version published in 2016). The IUCN Red List of Threatened Species 2009: e.T14734A86247230. DOI: 10.2305/IUCN.UK.2009.RLTS.T14734A4458480.en. [13 October 2019].

Pearson RG, Dawson TP. 2003. Predicting the impacts of climate change on the distribution of species: are bioclimate envelope models useful?. Global Ecol Biogeogr 12: 361-371.

Peterson AT, Papes M, Soberón J. 2008. Rethinking receiver operating characteristic analysis applications in ecological niche modeling. Ecol Model 213 (1): 63-72

Peterson AT, Soberón J, Pearson RG, Anderson RP, Martínez- Meyer E, Nakamura M, Araújo MB. 2011. Ecological Niches and Geographic Distributions. Princeton University Press, Princeton, NJ.

Phillips SJ, Anderson RP, Dudík M, Schapire RE, Blair ME. 2017. Opening the black box: an open-source release of Maxent. Ecography 40: 887-893.

Phillips SJ, Anderson RP, Schapire RE. 2006. Maximum entropy modeling of species geographic distributions. Ecol Model 190: 231259.

Phillips SJ, Dudik M. 2008. Modeling of species distributions with Maxent: new extensions and a comprehensive evaluation. Ecography 31: 161-175.

Riahi K, van Vuuren DP, Kriegler E, et al. 2017. The Shared Socioeconomic Pathways and their energy, land use, and greenhouse gas emissions implications: An overview. Global Environ Ch 42: 153-168.

Sayım F, Başkale E, Tarkhnishvili D, Kaya U. 2009. Some water chemistry parameters of breeding habitats of the Caucasian salamander, Mertensiella caucasica in the Western Lesser Caucasus. Comptes Rendus Biologies 332: 464-469.

Sharifi M, Shafiei Bafti S, Papenfuss T, Anderson S, Kuzmin S, RastegarPouyani N. 2009. Neurergus microspilotus (errata version published in 2016). The IUCN Red List of Threatened Species 2009: e.T59451A86642381.

DOI: 10.2305/IUCN.UK.2009.RLTS.T59451A11944058.en. [13 October 2019]. 
Smeraldo S, Di Febbraro M, Bosso L, Flaquer C, Guixé D, Lisón F, Meschede A, Juste J, Prüger J, Puig-Montserrat X, Russo D. 2018 Ignoring seasonal changes in the ecological niche of non-migratory species may lead to biases in potential distribution models: lessons from bats. Biodiv Conserv 27: 2425-2441.

Slater H, Michael E. 2012. Predicting the current and future potential distributions of lymphatic filariasis in Africa using maximum entropy ecological niche modelling. PLoS One 7: e32202. DOI: 10.1371/journal.pone.0032202.

Thuiller W, Lavorel S, Araujo MB, Sykes MT, Prentice IC. 2005. Climate change threats to plant diversity in Europe. Proc Natl Acad Sci USA 102: $8245-50$.

UNEP-WCMC 2019. Protected Area Profile for Iraq from the World Database of Protected Areas, September 2019. Available at: www.protectedplanet.net

van Vuuren DP, Edmonds JA, Kainuma M, Riahi K, Weyant J. 2011. A special issue on the RCPs. Clim Ch 109: 1-4.

Vasconcelos TS, Nascimento BTM. 2014. The utility of open-access biodiversity information in representing anurans in the Brazilian Atlantic Forest and Cerrado. Phyllomedusa: J Herpetol 13: 51.

Vasconcelos TS, Rodríguez MÁ, Hawkins BA. 2012. Species distribution modelling as a macroecological tool: a case study using New World amphibians. Ecography 35: 539-548.

Wayne G. 2013. The Beginners's Guide to Representative Concentration Pathways. Skeptical Science. https://skepticalscience.com/docs/RCP_Guide.pdf
Warren DL, Seifert SN. 2011. Warren_Ecological niche modeling in Maxent- the importance of model complexity and the performance of model selection criteria. Ecol Appl 21: 335-342.

Warren DL, Glor RE, Turelli M. 2008. Environmental niche equivalency versus conservatism: Quantitative approaches to niche evolution. Evolution 62: 2868-2883.

Whittaker RJ, Araújo MB, Jepson P, Ladle RJ, Watson JEM, Willis KJ. 2005. Conservation biogeography: assessment and prospect. Divers Distrib 11: 3-23

Wiens JJ. 2011. The causes of species richness patterns across space, time, and clades and the role of 'ecological limits'. Q Rev Biol 86: 75-96.

Widick IV, Bean WT. 2019. Evaluating current and future range limits of an endangered, keystone rodent (Dipodomys ingens). Divers Distrib 2019: 1-14. DOI: 10.1111/ddi.12914.

Williams DF. 1992. Geographic distribution and population status of the giant kangaroo rat, Dipodomys ingens (Rodentia, Heteromyidae). In Endangered and sensitive species of the San Joaquin Valley, California: Their biology, management, and conservation. California Energy Commission \& California State University Bakersfield, Bakersfield, CA.

Wisz MS, Pottier J, Kissling WD, et al. 2013. The role of biotic interactions in shaping distributions and realised assemblages of species: implications for species distribution modeling. Biol Rev 88: 15-30. 